\title{
Military Expenditure, Threats, and Growth ${ }^{*}$
}

March 19, 2003

\author{
Joshua Aizenman \\ Department of Economics \\ University of California, Santa Cruz \\ jaizen@ucsc.edu
}

\author{
Reuven Glick \\ Economic Research Department \\ Federal Reserve Bk. of San Francisco \\ Reuven.Glick@sf.frb.org
}

\begin{abstract}
This paper clarifies one of the puzzling results of the economic growth literature: the impact of military expenditure is frequently found to be non-significant or negative, yet most countries spend a large fraction of their GDP on defense and the military. We start by empirical evaluation of the non-linear interactions between military expenditure, external threats, corruption, and other relevant controls. While growth falls with higher levels of military spending, given the values of the other independent variables, we show that military expenditure in the presence of threats increases growth. We explain the presence of these nonlinearities in an extended version of Barro and Sala-i-Martin (1995), allowing the dependence of growth on the severity of external threats, and on the effective military expenditure associated with these threats.
\end{abstract}

\footnotetext{
* We thank Marc Meredith for research assistance. The views presented in this paper are those of the authors alone and do not necessarily reflect those of the NBER, the Federal Reserve Bank of San Francisco or the Board of Governors of the Federal Reserve System.
} 


\section{Introduction}

This paper studies the long-run impact of military expenditure on growth. A well known empirical regularity is the low impact of government expenditure on growth. This result was obtained in Barro's cross-country growth regression investigation, where the coefficient of government expenditure on growth is frequently non-significant. This finding applies also for military expenditures, the impact of which is frequently found to be non-significant or negative (see Barro and Sala-i-Martin, 1995). ${ }^{1}$

We conjecture that these findings are due to non-linearities and omitted variable biases. Consequently, the ultimate growth effects of military expenditure can be traced only after controlling properly for the interaction between the intensity of threats and military expenditure. We validate this conjecture by estimating growth equations for a cross-section of countries over the period 1989-98, identifying the presence of non-linear interaction between threats and military expenditure. This is done by adding a constructed measure of military threats to the conventional growth regressions, allowing for non-linear interactions. Our findings validate the conjecture, showing that military expenditure in the presence of threats increases growth.

We provide the theoretical underpinning for the interaction between military expenditure and threats by extending Barro and Sala-i-Martin (1995) to account for the impact of military expenditure on growth. We do it in a framework that recognizes the adverse impacts of hostile external threats and actions on growth, in the presence of rent seeking and corruption. We also provide empirical evidence of non-linear interaction effects of corruption when analyzing the impact of military spending on growth.

We close the paper with discussion of possible extensions to the analysis of the analysis. We suggest avenues for further empirical examination of the relation between growth and military

\footnotetext{
${ }^{1}$ For an overview of the literature on defense expenditure and growth see Ram (1995). See also Chowdhury (1991), Mintz and Stevenson (1995), Landau (1996), and Knight, Loayza and Villanueva (1996).
} 
spending. We also discuss extensions to the theoretical framework, including possible linkages between military expenditure and the economic structure through R\&D spending, human capital accumulation, and learning by doing.

\section{Threats, Military Expenditure and Growth: Empirical Evidence}

We start the investigation with the following conjecture:

- The impact of military expenditure on growth is a non-linear function of the effective militarized threat posed by foreign countries and other external forces. Threats without expenditure for military security reduce growth, military expenditure without threats would reduce growth, while military expenditure in the presence of sufficiently large threats increases growth.

More specifically, denoting real growth by gy military expenditures by mil, and a country's effective threat by $t h r$, our conjecture may be expressed as

$$
\begin{array}{ll}
\frac{\partial g y}{\partial m i l}=a_{1}+a_{2} t h r ; & a_{1}<0, a_{2}>0 \\
\frac{\partial g y}{\partial t h r}=b_{1}+b_{2} m i l ; & b_{1}<0, b_{2}>0
\end{array}
$$

This in turn suggests a growth equation specification of

$$
g y=a_{1} m i l+a_{2}(t h r)(m i l)+b_{1} t h r+\beta X ; \quad a_{1}<0, b_{1}<0, a_{2}>0
$$

where $X$ is a set of control variables. ${ }^{2}$ The direct effects of military spending and external threats on growth are assumed negative, while the interactive effect is positive.

As a preliminary effort to empirically support our conjecture, we provide results from estimating the growth equation above for a cross-section of countries over the period 1989-98.

\section{Description of Data}

We construct gy from data on real per capita GDP from the Penn World Tables, version 6.1 (PWT6.1). Transition countries are excluded from the sample.

mil is measured as the average of the ratio of nominal military expenditures to nominal GDP over the period 1989-98, using data obtained from the World Bank World Development

\footnotetext{
${ }^{2}$ For simplicity, $a_{2}$ is constrained equal to $b_{2}$. These coefficients would differ in circumstances where growth is impacted by higher moments of mil and $t h r$.
} 
Indicators 2002 CD-ROM. ${ }^{3}$ Since this source provides data on military spending for the years 1989-98 only, this effectively constrained the length of the time series used in constructing our cross-section averages; in future work we intend to extend the series from other sources. ${ }^{4}$

We proxy a country's degree of external threat by counting the number of wars and adversaries against whom it has been involved in conflict. Specifically, thr is defined as the number of years a country was at war with each of its adversaries during the period 1970 to 1998 summed over the set of its adversaries. Thus the external threat faced by a country rises with the number of wars in which is has been engaged, the number of adversaries it faces in each war, as well as with the number of years that each war persists. ${ }^{5}$ This variable was constructed from data on militarized interstate disputes collected by the Correlates of War Project (COW) at the University of Michigan. ${ }^{6}$

${ }^{3}$ The World Bank reports the ratio of military expenditures to GNP; we converted these figures into ratios relative to GDP.

${ }^{4}$ The source of the World Bank data on military spending is the Arms Control and Disarmament Agency (ACDA). While the ACDA has reported figures for 10-year rolling periods in its (more or less) annual publication World Military Expenditures and Arms Transfers as far back as the 1960s, various problems of consistency must be addressed before they can be assembled into a single panel time series. The main problem concerns how the ACDA converts local currency spending data into current or real dollar terms for comparison across countries and time; this problem is much less severe when the spending data is scaled by GDP. An alternative source sometimes used by other researchers in this area is the Stockholm International Peace Research Institute (SIPRI). However, the SIPRI data face consistency issues as well; moreover, its country coverage is smaller than that provided by the ACDA. For a comparison of problems with military spending data from various sources, see Happe and WakemanLinn (1994).

${ }^{5}$ Possible permutations of this measure include weighting conflicts by their intensity or by the timing of their occurrence, including potential threats from neighbors or other countries that did not manifest themselves in actual wars over the period, and taking account of the military capabilities of actual or potential adversaries. Another possible extension of our analysis is taking account of the occurrence of civil wars and internal threats that may also influence the magnitude of military spending. We will pursue permutations of our threat measure that take account of these factors in future research.

${ }^{6}$ We use Zeev Maoz's dyadic data set DYMID1.1, a revised version of the COW dataset for MID2.1 (webpage: http://spirit.tau.ac.il/zeevmaoz). This data set codes the level of hostility reached in a given country's conflict with other opposing state(s), where $2=$ threat of force, $3=$ display of force, $4=$ use of force (short of war), and 5 = war. We construct our threat variable with disputes of hostility level 5 , which generally involve more than 1,000 battle deaths. The data set is extended from 1992 through 1997 with information on "Major Episodes of Political Violence, 1946-1999" from the University of Maryland's Center for Systemic Peace (CSP) and The Statesman's Yearbook (webpage: http://members.aol.com/CSPmgm/cspframe.htm). 
We also include a standard set of control variables typically used in the empirical growth literature (e.g. Barro and Sala-i-Martin, 1995, Ch. 12). These controls include the initial levels of per capita real GDP and education, population growth, and the investment rate, among other variables. More specifically, our control variables include $\lg d p$, the log of real per capita GDP in 1975; leduc, the log of the number of years of schooling attained by males aged 25 and over at the secondary and higher levels in 1975; gpop, population growth over 1989-98; and inv/gdp, the average real investment/ GDP ratio over 1984-88. Data on GDP levels, population, and investment/GDP ratios are drawn from PWT6.1; the education data are taken from the from Barro-Lee data set (website:www2.cid.harvard.edu/ciddata/barrolee). ${ }^{7}$

Summary statistics for mil, thr, gy, and our other control variables are shown in Table 1. Military spending as a share of GDP ranges from 0 to more than 40 percent (for Kuwait). Our threat count variable ranges from 0 to 15 (for Vietnam). ${ }^{8}$ The unconditional correlation of mil and $t h r$ is 0.33 , and the correlation conditioned on data availability for the variables in our growth equation is 0.48 , implying countries with higher levels of military spending also tend to face greater external threats. Figure 1 gives a scatter plot illustrating the same positive relation between these variables (with observations indicated by three-letter country labels). ${ }^{9}$ This finding supports our view of the importance of taking account of the interaction of military spending and the level of "need" for military services when analyzing the impact of military spending on economic growth.

\footnotetext{
${ }^{7}$ The education data is available for only 99 countries and is the main constraint on the number of countries included in our cross-section regression analysis.

${ }^{8}$ Kuwait and Vietnam are both eliminated when the sample is conditioned on the availability of all of the variables entering into our growth equation specification. In the latter case, Israel is the country with the highest level of mil (10.5 percent of GDP) and Iran is the country with the highest value of thr (9).

${ }^{9}$ The observations are conditioned on data availability for all of the variables in the estimated growth equation.
} 


\section{$\underline{\text { Empirical Results }}$}

We test the relationship among our variables more formally by estimating our growth equation with ordinary least squares. ${ }^{10}$ The results are shown in Table 2.

The control variables have the expected signs and are significant at conventional levels. Per capita growth depends positively on the education level and investment rate and negatively on population growth. We also find evidence of the usual conditional convergence result: countries with high initial income levels grow more slowly. ${ }^{11}$

The three columns of Table 1 compare the effects on growth of including our measures of military spending and external threat.

Column (1) in Table 1 shows the effect of including only the ratio of military spending to GDP. The estimated coefficient is negative, but is highly insignificant (the p level is .59). This result accords with that of Barro (1991a, 1991b) and Barro and Sala-i-Martin (1995) who fail to find any significant effect of military spending on growth. ${ }^{12}$ As shown in column (2), adding our threat measure as an explanatory variable, increases the magnitude (in absolute value) of the coefficient on military spending, but it is still not significant at conventional levels (the p-level is 0.11). Moreover, the coefficient on $t h r$, though very significant, is positive, implying that external conflicts have a positive effect on growth, contrary to our expectation.

\footnotetext{
${ }^{10}$ We ignore concerns about the possibly endogeneity of our explanatory variables. We also do not take account of the possible impact of military spending on physical or human capital investment. To the extent that military spending crowds out such investment, our results should understate the impact of military expenditures on growth.

${ }^{11}$ Our estimated conditional rate of convergence ranges from 1.6 to 1.9 percent (in absolute value) and is somewhat smaller than that found by others. This can be attributed to the fact that other studies typically measure growth over a much longer perio $\mathrm{d}-25$ to 30 years-compared to our period length of only 11 years.

${ }^{12}$ Barro (1991a, 1991b) finds no effect of military spending on growth for a single cross-section of countries over the period 1960-85, while Barro and Sala-i-Martin (1995, Table 12-3) find no effect when the sample consists of two nonoverlapping panels of ten years each for the period 1965-85. Martin Knight, Loayza, and Villanueva (1996) also find that the military spending ratio has an insignificant effect on growth in a cross-section over the 1971-85 period; however, the effect is significant and negative when they utilize a panel estimator applied to three non-overlapping five-year periods. These studies all include a separate dummy variable indicating whether a country participated in one or more wars over the sample period.
} 
However, as shown in column (3), including an interactive term involving mil and thr provides support for our conjecture. mil now has a very significant (at better than $1 \%$ ) and negative direct effect on growth. The coefficient on thr is now negative, as expected (though it is not significant), implying a higher level of external threat directly reduces growth.

The coefficient on the interactive term is significant (at a 5\% level) and positive, as conjectured: the presence of threats (algebraically) raises the marginal impact of military expenditures on growth.

In fact, the coefficients on mil and mil*thr imply that for threat levels below (above) 3.5 $(=0.56 / 0.16)$ greater military spending has an overall negative (positive) effect on growth. Quantitatively, the estimated impact of military spending ranges from a low of -0.56 for countries with no threats to a high of 0.88 for a country with the maximum threat level. ${ }^{13}$ That is, the effect of a 1 percentage point increase in the military spending/GDP ratio varies from a reduction in growth by almost 0.6 of a percentage point to an increase in growth by almost 0.9 percentage points. [J: Last sentence may be redundant, but I wanted to clarify the units.]

As a check on the results, the growth equation was reestimated by interacting mil with two separate dummy variables: one for countries facing low threats, i.e. with values of thr less than 3.5 (the break point level identified above), and the other for countries with high threat levels, i.e. with values of $t h r$ greater than 3.5. (Separate intercepts for low and high threat countries were also included in place of a common constant term.) This specification results in an estimated coefficient for $m i l$ of -0.47 (s.e. $=0.20$ ) in the low threat range and of 0.26 (s.e. $=0.27$ ) in the high threat range. That is, the effect of mil on growth is negative when $t h r$ is low and positive when $t h r$ is high. ${ }^{14}$ These estimated coefficients are jointly significantly different from zero (pvalue $=0.04)$ and also significantly different from each other $(p$-value $=0.03)$ Thus this piecewise linear specification implies a relationship similar to that found in the specification including the interaction term between mil and thr.

\footnotetext{
${ }^{13}$ Since the sample median of $t h r$ is 0 , when evaluated at this value of of $t h r$ the marginal effect of military spending on growth is also -.56. When evaluated at the sample mean of $t h r(0.76)$, an increase in military spending reduces growth by $(0.56-0.16 * 0.76=) 0.44$ of a percentage point.

${ }^{14}$ Note that the negative direct effect of $t h r$ on growth implies that greater threat levels do not necessarily lead to an overall rise in growth.
} 
Figures 2 and 3 graphically illustrate the relationship among growth, military spending, and threats. Figure 2 shows the partial relation between growth and military spending, as implied by the regression from column 3 of Table 2, with the interaction effect of mil and thr included. The horizontal axis plots military spending for the countries included in the regression sample. The vertical axis shows the corresponding growth rate of GDP after filtering out the effects explained by all explanatory variables other than mil, including the direct effect of $t h r$ and the interactive term. ${ }^{15}$ The negative slope apparent in the scatter plot is consistent with the negative relation reported for the regression; that is, growth falls with higher levels of military spending, given the values of the other independent variables (including the interaction effect).

Figure 3 shows the partial relations between the growth rate and military spending ratio for the low and high ranges of the threat variable identified earlier. In the top panel, where thr is below 3.5, the estimated relation is negative. In the bottom panel, where thr is above 3.5, the estimated relation is positive.

\section{Theoretical Model}

We model the interaction of growth, military spending, and external threats by extending Barro (1990). To simplify, we assume zero population growth. Output per worker is impacted positively by infrastructure supplied by the public sector, and negatively by the magnitude of the external threat. The reduced form of output is

$$
y=A(k)^{1-\alpha}(g)^{\alpha} f
$$

where $A$ is an exogenous productivity factor, $k$ is the capital/labor ratio, $g$ is the infrastructure/labor ratio, and 1 - $f$ measures the output cost of the threat posed by foreign rivals' actual or potential hostile actions. We assume that this cost depends negatively on domestic

\footnotetext{
${ }^{15}$ The residual is calculated from the regression that contains all of the variables, including mil, thr, and $m i l^{*} t h r$. But the contribution from military spending is left out when computing the unexplained part of gy plotted on the vertical axis in the scatter diagram. Constructing residual growth in this manner implicitly evaluates the marginal effect of military spending by assuming each country faces no external threat. (The residuals are normalized to have a mean of 0 .)
} 
military expenditures and positively on an index of the magnitude of the threat; for simplicity we adopt the following functional form: ${ }^{16}$

$$
f\left(g_{m}, z\right)=\frac{g_{m}}{g_{m}+z} ; \quad f_{g_{m}}>0, f_{z}<0, f(0, z)=0, f(\infty, z)=1,0<f<1
$$

where $g_{m}$ is domestic military expenditure and $z$ is the foreign threat level. Note that this specification implies that $z$ is measured in units comparable to that of domestic military expenditure so that $g_{m}$ and $z$ may be aggregated. ${ }^{\mathbf{1 7}}$

Corruption may also be introduced into the model as activity that taxes fiscal expenditures on military and non-military government spending at a rate of $t_{c}$. Hence, output with corruption is

$$
y=A(k)^{1-\alpha}\left(g\left[1-t_{c}\right]\right)^{\alpha} \frac{g_{m}\left[1-t_{c}\right]}{g_{m}\left[1-t_{c}\right]+z}
$$

We denote the ratio of military to non-military infrastructure expenditure by $\phi$,

$$
g_{m}=\phi g .
$$

Thus, the total fiscal outlay on both military and non-military spending is $(1+\phi) g{ }^{18}$

The rest of the model's specification is identical to that of Barro (1990). The fiscal outlay is financed by a proportional tax $\tau$ :

$$
(1+\phi) g=\tau y \text {. }
$$

The representative agent's preferences are

$$
U=\int_{0}^{\infty} \frac{c^{1-\sigma}-1}{1-\sigma} \exp (-\rho t) d t
$$

\footnotetext{
${ }^{16}$ This form allows a tractable solution. Our analysis applies for other functional forms, including a logistic specification. See Hirshleifer (1995), Skaperdas (1996), and Epstein (1997) for models of military conflicts illustrating the importance of considering relative military efforts among rivals in modeling and determining conflict outcomes.

${ }^{17}$ This suggests that the external threat level may be proxied by the level of foreign military expenditures, rather than the incidences of conflict between the domestic country and its foreign rivals, as in our empirical analysis in Section 2.

${ }^{18}$ Note that the share of military spending out of total government expenditures is $g_{m} /\left(g_{m}+g\right)=\phi /(1+\phi)$; the military spending-to-output ratio is $g_{m} / y=\phi \tau /(1+\phi)$. Also note that, though $g_{m} /\left(g_{n}+g\right)$ and $g_{m} / y$ are bounded by $1, \phi$ is not.
} 
Following the methodology described in Barro (1990), it follows that the output growth rate is

$$
\gamma=\frac{\dot{y}}{y}=\frac{1}{\sigma}\left[(1-\tau) \frac{\partial y}{\partial k}-\rho\right] .
$$

The optimal pattern of taxes and spending (denoted by $\tilde{\tau}, \tilde{\phi}$ ) that determine the size of the military sector and maximize the growth rate is given by ${ }^{19}$

$$
\begin{aligned}
& \tau=\alpha(1+\tilde{\phi}) \\
& (\tilde{\phi})^{2} \alpha\left[\alpha\left(1-t_{c}\right)\right]^{\frac{1}{1-\alpha}}[1-\alpha \tilde{\phi}]^{\frac{\alpha}{1-\alpha}} A^{\frac{1}{1-\alpha}}=\frac{z}{k}
\end{aligned}
$$

Equation (8a) equates the tax rate $\left(\tau=\left(g+g_{m}\right) / y\right.$, and thereby also the government's expenditure share) to the output elasticity with respect to the marginal product of nonmilitary spending, $\alpha$, magnified at the rate $\phi$ ( the ratio of military to non-military government expenditure). ${ }^{20}$ In the absence of military spending, (8a) reduces to $\tau=\alpha$, the standard production efficiency condition, as derived by Barro (1990). From equation (8b) we can infer that the military expenditure ratio, $\phi$, depends positively on the external threat (normalized by the domestic stock of capital), positively on the corruption level, and negatively on the productivity level:

$$
\tilde{\phi}=\tilde{\phi}\left(z, t_{c}, A\right) ; \quad \tilde{\phi}_{z}>0, \tilde{\phi}_{t_{c}}>0, \tilde{\phi}_{A}<0 ; \tilde{\phi}\left(0, t_{c}, A\right)=0
$$

Correspondingly, from (8a) it follows

$$
\tilde{\tau}=\tilde{\tau}\left(z, t_{c}, A\right) ; \quad \tilde{\tau_{z}}>0 ; \quad \tilde{\tau}_{t_{c}}>0 ; \quad \tilde{\tau}_{A}<0
$$

Figure 4 plots the relation between military spending and the threat level implied by (8b) and (9). ${ }^{21}$ In the absence of threats, $z=0$, then $\tilde{\phi}=0$, i.e. the optimal amount of military spending is

${ }^{19}$ See the mathematical appendix for the derivation. These results were obtained by solving
simultaneously the first-order conditions associated with the problem of $\max _{\phi, \tau}[\gamma]$. This maximization
is subject to the constraints imposed by (3)-(5), applying the implicit function theorem. We assume that
the magnitude of the productivity coefficient and the rate of time preference meet the conditions leading
to positive endogenous growth. See Barro (1990) and Barro and Sala-i-Martin (1995) for further details.

${ }^{20}$ With optimally set tax and expenditure rates, it is straightforward to show that $g / y=\alpha$ and $g_{m} / y=\alpha \tilde{\phi}$.

${ }^{21}$ Figure 3 is calibrated by assuming $A=1, \alpha=.2$, and $t_{c}$ set equal to .1 or .2 
zero. For positive threat levels, $z>0$, however, $\tilde{\phi}>0$, i.e. the optimal level of military spending is positive. As the threat level increases, the optimal amount of military spending increases monotonically. Figure 4 also illustrates the effect of parametrically increasing the corruption rate, $t_{c}$. The solid line depicts the benchmark relation between $\phi$ and $z$ (for $t_{c}=.1$ ); the dashed line depicts the effect of increasing the corruption rate (to $t_{c}=.2$ ). Evidently, higher corruption implies a higher optimal level of military spending for any given threat level.

A useful characterization of equilibrium government spending is that the optimal share of military expenditure is proportional to the output cost of external threats, $1-f$ (see the appendix for the derivation):

$$
\tilde{\phi}=\frac{1-f}{\alpha} .
$$

In the absence of threats, the optimal level of military spending is zero, the output cost of threats is zero $(f=1)$, and output is a standard CRS function of $k$ and $g$ (see equation (1)). Correspondingly, the optimal tax rate $(\tilde{\tau})$ equals the output share of government services $(\alpha)$, and is independent of scale effects (as follows from (8a) and (10)). The presence of threats and hostile actions, however, implies positive military spending and output costs $(f<1)$, and adds a non-linear multiplicative term $(f)$ to output.

This in turn adds a scale consideration to the design of optimal tax and spending rates, summarized by (see the appendix):

$$
\alpha \tilde{\phi}=1-f=\frac{z}{\tilde{g}_{m}\left(1-t_{c}\right)+z}
$$

where $\tilde{g}_{m}=\frac{\tilde{\phi} \tilde{\tau} \tilde{y}}{1+\tilde{\phi}}$. The optimal ratio of military to non-military government spending $(\tilde{\phi})$ times the output share of nonmilitary spending $(\alpha)$ equals the output cost of external threats $(1-f)$, which in turn equals the magnitude of the foreign threat $(z)$ relative to the aggregate effective military expenditure by the domestic country and its foreign rival $\left(\widetilde{g}_{m}\left(1-t_{c}\right)+z\right)$, where "effective" implies net of corruption tax. Consequently, an exogenous increase in the foreign threat level, $z$, increases the optimal spending and tax rates, $\tilde{\phi}$ and $\tilde{\tau}$.

Hence, the foreign hostility level impacts growth adversely due to two compounding effects: the direct adverse growth effect associated with the resultant drop of the marginal product of 
capital (see equation (7)), magnified by the adverse effects associated with the higher tax rate induced by lower productivity. Applying the same logic, it follows that higher corruption $\left(t_{c}\right)$ and lower domestic productivity $(A)$ increase military spending and the optimal tax rate and reduce growth. Accordingly, we can derive the following reduced-form expression for optimal output growth:

$$
\tilde{\gamma}=\tilde{\gamma}\left(z, t_{c}, A\right) ; \tilde{\gamma}_{z}<0, \tilde{\gamma}_{t_{c}}<0, \tilde{\gamma}_{A}>0
$$

In addition, we may determine that (see the appendix for the derivation)

$$
\frac{\partial \tilde{\gamma}}{\partial \tilde{\phi}}<0 \text { and } \frac{\partial^{2} \tilde{\gamma}}{\partial \tilde{\phi} \partial z}>0
$$

thus confirming the nonlinear theoretical relationship between growth and military spending that we conjectured and tested empirically in Section 2.

We illustrate these results in Figure 5, which plots the corresponding relation between the optimal levels of growth and military spending, while holding constant the levels of external threat and corruption. ${ }^{22}$ Higher military spending reduces growth, ceteris paribus. A higher threat level shifts the entire locus upward.

\section{Military Expenditure, Corruption, and Growth: Empirical Evidence}

Our theoretical model suggests that the relation between military expenditure and growth also depends on corruption and rent seeking behavior. In particular, by acting as a tax on fiscal expenditures, corruption raises the desired level of military spending. Accordingly, we conjecture:

- The impact of military expenditure on growth is a non-linear function of the level of corruption. Military expenditure in the presence of corruption reduces growth.

\footnotetext{
${ }^{22}$ Figure 5 is calibrated by assuming $\alpha=.2, t_{c}=.1, \sigma=1, \rho=.02, \quad z / k=.0001$ (for the solid line), $z / k=.001$ (for the dashed line), and parametrically varying $A$ to determine $\tilde{\phi}$ and $\tilde{\gamma}$. See the appendix.
} 
In this section we present some empirical evidence concerning the association between military spending, corruption, and growth. ${ }^{23}$ We initially abstract from the role of external threats considered in the empirical analysis of Section 2.

As our measure of corruption, we employ the index constructed by Tanzi and Davoodi (1997) based on data from Business International (BI) and the International Country Risk Guide (ICRG). The Tanzi-Davoodi measure, ranges from 0 (most corrupt) to 10 (least corrupt), and hence may be interpreted as an increasing index of "good government" practices. ${ }^{24}$ The explanatory variable goodgov is defined as the average level of this index over the period 1989$95 .^{25}$ The unconditional correlation of mil and goodgov is -0.18 , implying that the military spending share of GDP tends to fall with good government and rise with corruption. ${ }^{26}$ However, when the sample is restricted only to countries with data available for all of the variables in our growth equation, the correlation is only -.02. ${ }^{27}$ Figure 6 plots the good government index against the ratio of military spending to GDP for this restricted sample. No clear relationship is apparent in the scatter.

Table 3 reports the effects of including corruption in our model of growth, along with the same control variables used in Table 2; a dummy for sub-Saharan African countries has also been added.

As column (1) of Table 3 indicates, the coefficient on our good government variable is positive and significant, implying better government and less corruption has a positive effect on

${ }^{23}$ See Gupta, de Mello and Sharan (2000) for evidence that corruption raises military spending with a panel data set covering the period 1985-98.

${ }^{24}$ The BI index ranges from 0 to 10, while the ICRG index ranges from 1 to 6. Tanzi and Davoodi splice the two series together to form a single 0-10 index for 1980 to 1995. The Tanzi-Davoodi measure refers specifically to the extent of bribes and other illegal payments demanded by government officials in business dealings and other transactions. The ICRG also collects data on a number of other measures of institutional quality, including maintenance of the rule of law, quality of the bureaucracy, risk of expropriation, and risk of repudiation of government contracts.

${ }^{25}$ Our results below are unaffected if we define goodgov as the level of corruption for 1989, the initial year of our sample.

${ }^{26}$ A linear regression of mil on goodgov gives a coefficient of .47, with t-statistic of 1.99 .

${ }^{27}$ The observations are conditioned on data availability for all of the variables in the estimated growth equation reported in Table 3 below. 
growth. ${ }^{28}$ An improvement in the good government index by one unit (on a scale of 0 to 10) is estimated to raise the growth rate by 0.50 percentage point. ${ }^{29}$ This finding accords with that of Mauro (1995), among others. ${ }^{30}$ Column (2) indicates that the significance of corruption is robust to adding the ratio of military spending to GDP, but the latter is highly insignificant (the p level is 0.85$)$. However, as shown in column (3), including an interactive term involving mil and goodgov provides support for a nonlinear relation between military spending, corruption, and growth. mil now has a very significant (at better than 1\%) and negative direct effect on growth. The direct effect of goodgov on growth is now insignificant, but the coefficient on the interactive term is significant (at a 1\% level) and positive, implying military expenditure in the presence of better government raises growth. ${ }^{31}$ This result is consistent with our model.

In fact, the coefficients on mil and mil*goodgov imply that for threat levels above 6.35 $(=1.27 / 0.20)$ greater military spending has an overall positive effect on growth. Analogously to our analysis of the role of external threats, the growth equation was reestimated by interacting goodgov with separate dummy variables for countries with low and high levels of goodgov, i.e. with values of goodgov less than and greater than the cutoff value of 6.35, respectively. (Separate intercepts were also included in place of a common constant term.) This specification results in an estimated coefficient for goodgov of -0.35 (s.e. $=0.17$ ) in the low range and of 0.26 (s.e.=0.19) in the high range. That is, the effect of mil on growth is negative when goodgov is low and positive when it's high. These estimated coefficients are jointly significantly different from zero $(p$-value $=0.03)$ and also significantly different from each other $(p$-value $=0.01)$ Thus

\footnotetext{
${ }^{28}$ This marginal effect is calculated conditional on a country having the highest level of corruption, i.e. goodgov $=0$. When evaluated at the sample median of goodgov (5.36), an increase in military spending reduces growth by only $(-1.27+0.20 * 5.36=)-0.20$ of a percentage point. When evaluated at the sample mean of goodgov (6.00), an increase in military spending reduces growth by $(-1.27+0.20 * 6.0$ $=)-0.07$.

${ }^{29}$ Since the standard deviation of the goodgov variable is 2.31 , a one standard deviation improvement would imply growth falls by .22 of a percentage point.

${ }^{30}$ Tanzi and Davoodi $(1997,2000)$ find indirect evidence that corruption decreases growth by reducing government revenue and the productivity of public investment. Barro and Sala-i-Martin (1995), find that the ICRG's "rule of law" measure of institutional quality has a positive effect on growth.

${ }^{31}$ The coefficients on $m i l$ and $m i l *$ goodgov imply that for index levels of good government above 6.35 $(=1.27 / 20)$, (on a scale of $0-10$ ), greater military spending has a positive effect on growth.
} 
this piece-wise linear specification implies a relationship similar to that found in the specification including the interaction term between $\mathrm{mil}$ and $t h r$.

Figure 7 plots the partial relation between growth and military spending, as implied by the regression from column (3) of Table 3. The vertical axis shows the growth rate of GDP after filtering out the effects explained by all explanatory variables other than mil (including the direct effect of goodgov and the interactive term). The negative slope apparent in the scatter plot is consistent with the negative relation reported for the regression; that is, growth falls with higher levels of military spending, given the values of the other independent variables, including corruption.

These results highlight the need to control for nonlinear interaction effects of corruption when analyzing the effect of military spending on growth.

We conclude this section by simultaneously considering the empirical effects of external threats and corruption on military spending and growth. We do so by dividing our sample into two subsamples according to the mean level of corruption, 6.00. Table 4 reports the results of estimating the nonlinear effects of military spending and threats on growth for each of these two samples. As shown in Column (1), the coefficient on mil and mil*thr have the expected negative and positive signs, respectively, for "high" corruption countries, i.e. the countries with low indices of good government (goodgov < 6.0). For this subsample, the estimated coefficient for mil is -0.81 and significant at $1 \%$; the coefficient on the interaction term is 0.22 and significant at better than 5\%. ${ }^{32}$ In contrast, for the "low" corruption countries (i.e. goodgov > 6.0), the coefficients on mil and the interaction term are insignificant (and the coefficient on mil is actually positive in sign). Thus the effects of mil on growth in our sample appear to hold primarily for countries with greater corruption.

\section{Discussion and Future Research}

Our theoretical model suggests that military expenditure induced by external threats should increase growth (using the proper controls), while military expenditure induced by rent seeking and corruption should reduce growth. We have confirmed the basic conjectures implied by the

\footnotetext{
${ }^{32}$ The results are not effected if a dummy variable for sub-Saharan African countries is included.
} 
theoretical model regarding the nonlinear relation between military spending, corruption, and growth in a cross-country regression growth analysis.

Our analysis suggests a number of paths of future research concerning the relation of economic growth and military activity. One avenue is to investigate further the robustness and stability of our empirical results. Possible steps include:

- Analyze the sensitivity of the results to different measures of the external security threat by weighting conflicts by their intensity and/or timing in relation to current spending, taking account of military expenditure levels and capabilities of adversaries, and controlling for geography-related vulnerability factors, e.g. existence of common borders with adversaries, distance from adversaries, land border length, coastline length, etc.

- Consider the impact of other economic control variables, such as government spending on nonmilitary activities. ${ }^{33}$

- Consider the effect of political factors, such as the degree of political stability, the political orientation of the government, the political power of the military in society, and military aid from abroad.

- Take account of the occurrence of civil wars and internal threats that may influence military spending and growth.

- Expand the time series dimension of the dataset. This would permit comparison of the time-series and cross-section association of military spending and growth using various panel estimators, investigation of the extent to which the end of the Cold War has influenced military spending over time (thought the "peace dividend" effect), and analysis of the contemporaneous and lagged effects of conflict and spending on growth.

- Investigate possible channels through which military spending may (possibly endogenously) encourage corruption. For example, do imports from foreign arms suppliers foster bribery in order to secure military contracts? Where the military sector engages in commercial business operations or controls natural resources and competition is limited, are opportunities for corruption enhanced?

\footnotetext{
${ }^{33}$ See Hewitt (1992) and Davoodi, Clements, Schiff, and Debaere (2001) for analyses of the association of military spending and nonmilitary government spending.
} 
Another avenue of future research is to model and test the possibility that military expenditures generate growth externalities. Possible channels leading to potential positive externalities include R\&D and human capital accumulation. Negative externalities may arise from corruption and costly monitoring, or from wage effects on the nontraded goods sectors along the line of the "Dutch Disease." 34

Modeling these externalities can be done by going beyond the reduced-form "AK" type of growth model elaborated in equations (1)-(7). One approach is to apply a Lucas (1993) variant of a two-sector growth model, with one sector producing final output and the other sector producing human capital, which in turn is used as an input in final output production. Final output growth would then be dependent on human capital, the accumulation of which depends on education costs and learning-by-doing effects. In this model, low-income countries may underinvest in human capital because of capital market imperfections, such as prohibitively high education costs and a low initial endowment of human capital. In such countries, the wish to promote a "competitive" military capability may induce the government to engage in activities that effectively subsidize the formation of human capital, addressing indirectly the distortions induced by the capital market imperfections. If these effects were powerful enough (and if the military expenditure does not lead to countervailing adverse effects due to corruption and rent seeking), the net outcome would be growth enhancing.

One expects these effects to be weak in the poorest countries, as a threshold of resources and human capital may be necessary to allow formation of an effective education system. These effects would tend to be weak in rich countries as well, where high enough income per capita would allow the private sector to self-finance education. Consequently, it may be conjectured that it is primarily in middle income countries that military expenditures may deliver strong growth effects due to externalities operating via the education system.

These theoretical extensions suggest questions for further empirical research:

- Do positive growth externalities from military activities exist in countries where the human capital/worker ratio (or alternatively, the physical capital/labor ratio) in the military sector exceeds that in the overall economy?

\footnotetext{
${ }^{34}$ See van Wijnbergen (1984) for a model of the "Dutch Disease."
} 
- Are the externalities of military spending stronger in middle-income countries than in low or high-income countries, as the suggested extension to our model implies?

- What other factors determine the size of these externalities? e.g. Do they depend on the degree of market-orientation of the economy? Do international arms exports generate growth externalities? Does the composition of military spending, i.e. spending on military personnel vs. capital equipment (e.g. airplanes, tanks, etc.) matter? 


\section{Mathematical Appendix}

The purpose of this Appendix is to derive equations (8a) and (8b) and characterize the properties of the determinants of the optimal tax, spending, and growth rates. Note first that equations (3)-(5) define output as an implicit function of the tax rate , $\tau$, and military spending ratio, $\phi$ :

$$
y=y(\tau, \phi) .
$$

From (1) and (7) it follows that the optimization problem may be expressed as

$$
\max _{\{\tau, \phi\}} \gamma=\max _{\{\tau, \phi\}}\left[(1-\tau) \frac{\partial y}{\partial k}\right]=\max _{\{\tau, \phi\}}\left[(1-\tau) \frac{y(1-\alpha)}{k}\right] .
$$

The corresponding first-order conditions are:

$$
\frac{d y}{d \phi}=0 ; \quad y=(1-\tau) \frac{d y}{d \tau}
$$

where $\frac{d y}{d \phi} ; \frac{d y}{d \tau}$ are obtained from (A1). Applying (3)-(5) and the implicit function theorem, we find that

$$
\frac{d y}{d \phi}=0 \Leftrightarrow \frac{\alpha y}{1+\phi}-\frac{y}{\phi(1+\phi)} \frac{z}{g_{m}\left(1-t_{c}\right)+z}=0
$$

from which we infer that, for the optimal tax rate,

$$
\alpha \tilde{\phi}=1-f .
$$

Applying the implicit function theorem and (3)-(5) and collecting terms, we also find that

$$
\frac{d y}{d \tau}=\frac{y}{\tau} \frac{\alpha+\frac{z}{g_{m}\left(1-t_{c}\right)+z}}{1-\left[\alpha+\frac{z}{g_{m}\left(1-t_{c}\right)+z}\right]} .
$$

From substitution of (A6) into (A3) we infer that the FOC determining $\tilde{\tau}$ is

$$
y=(1-\tilde{\tau}) \frac{y}{\tilde{\tau}} \frac{\alpha+\frac{z}{g_{m}\left(1-t_{c}\right)+z}}{1-\left[\alpha+\frac{z}{g_{m}\left(1-t_{c}\right)+z}\right]} .
$$

Combining (A5) and (A7) we find that 


$$
\tilde{\tau}=\alpha(1+\tilde{\phi}) .
$$

To obtain a reduced-form solution for $\phi$, we next substitute out for $g$ in (3) with (4) and (5) as well as out for $f$ with (A5), and derive

$$
\tilde{y}=A^{1 /(1-\alpha)} k\left[\left(1-t_{c}\right) \alpha\right]^{\alpha /(1-\alpha)}(1-\alpha \tilde{\phi})^{1 /(1-\alpha)}
$$

Applying (4) and (5) to (A5) gives (11)

$$
\alpha \tilde{\phi}=\frac{z}{\frac{\tilde{\phi}\left(1-t_{c}\right) \tilde{\tau} \tilde{y}}{1+\tilde{\phi}}+z} .
$$

Substituting for $\tilde{y}$ in (11) with (A8) and for $\tilde{\tau}$ with (8a) gives (8b), a condition that defines $\tilde{\phi}$ implicitly:

$$
(\tilde{\phi})^{2} \alpha\left[\alpha\left(1-t_{c}\right)\right]^{\frac{1}{1-\alpha}}[1-\alpha \tilde{\phi}]^{\frac{\alpha}{1-\alpha}} A^{\frac{1}{1-\alpha}}=\frac{z}{k}
$$

To establish the properties of the determinants of optimal tax and growth rates, we logarithmically differentiate (8b) and use (8a) to obtain

$$
\frac{2(1-\tilde{\tau})+\alpha^{2} \tilde{\phi}}{\tilde{\phi}(1-\alpha \tilde{\phi})(1-\alpha)} d \tilde{\phi}=d \log \frac{z}{k}-\frac{1}{1-\alpha} d \log A-\frac{1}{1-\alpha} d \log \left(1-t_{c}\right)
$$

Equations (11) and (8a) then imply that

$$
\begin{aligned}
& \tilde{\phi}=\tilde{\phi}\left(z, t_{c}, A\right) ; \quad \tilde{\phi}_{z}>0, \quad \tilde{\phi}_{t_{c}}>0, \tilde{\phi}_{A}<0 . \\
& \tilde{\tau}=\tilde{\tau}\left(z, t_{c}, A\right) ; \quad \tilde{\tau}_{z}>0 ; \quad \tilde{\tau}_{t_{c}}>0 ; \quad \tilde{\tau}_{A}<0 .
\end{aligned}
$$

To determine the optimal growth rate $\tilde{\gamma}$, note that $\frac{\partial y}{\partial k}=\frac{y(1-\alpha)}{k}$ and (7) imply

$$
\tilde{\gamma}=\frac{1}{\sigma}\left[(1-\tilde{\tau}) \frac{\tilde{y}(1-\alpha)}{k}-\rho\right]
$$

Substituting for $\tilde{y}$ with (A8) and for $\tilde{\tau}$ with (8a) gives

$$
\tilde{\gamma}=\frac{1}{\sigma}\left[A^{1 /(1-\alpha)}\left[\left(1-t_{c}\right) \alpha\right]^{\alpha /(1-\alpha)}(1-\alpha)[1-\alpha(1+\tilde{\phi})](1-\alpha \tilde{\phi})^{1 /(1-\alpha)}-\rho\right]
$$


Recalling (8a), $1-\alpha(1+\tilde{\phi})=1-\tilde{\tau}>0$. Applying this relation to (A10), it follows that ${ }^{35}$

$$
\frac{\partial \tilde{\gamma}}{\partial \tilde{\phi}}<0, \frac{\partial^{2} \tilde{\gamma}}{\partial \tilde{\phi} \partial z}>0
$$

and

$$
\tilde{\gamma}=\tilde{\gamma}\left(z, t_{c}, A\right) ; \tilde{\gamma}_{z}<0, \tilde{\gamma}_{t_{c}}<0, \tilde{\gamma}_{A}>0
$$

${ }^{35}$ Specifically,

$\frac{\partial \tilde{\gamma}}{\partial \phi}=-\psi(1-\alpha \tilde{\phi})^{\frac{\alpha}{1-\alpha}}\{(1-\alpha)[1-\alpha \tilde{\phi}]+[1-\alpha(1+\tilde{\phi})]\}<0$

$\frac{\partial^{2} \tilde{\gamma}}{\partial \tilde{\phi} \partial z}=\alpha \psi(1-\alpha \tilde{\phi})^{\frac{\alpha}{1-\alpha}}(1-\alpha)\left[\frac{\alpha[1-\alpha(1+\tilde{\phi})]+2(1-\alpha \tilde{\phi})}{(1-\alpha)(1-\alpha \tilde{\phi})}+\right] \frac{\partial \tilde{\phi}}{\partial z}>0$

where $\psi \equiv \frac{A^{1 /(1-\alpha)}\left[\left(1-t_{c}\right) \alpha\right]^{\alpha /(1-\alpha)} \alpha}{\sigma}$ and $\frac{\partial \tilde{\phi}}{\partial z}>0$. 


\section{Data Appendix: Countries in Regression Samples}

\begin{tabular}{|c|c|c|c|c|c|}
\hline Country Name & Code & $\begin{array}{c}\text { Missing Corruption } \\
\text { Data }\left(^{*}\right)\end{array}$ & Country Name & Code & $\begin{array}{c}\text { Missing Corruption } \\
\text { Data }\left(^{*}\right)\end{array}$ \\
\hline Algeria & DZA & & Jordan & JOR & \\
\hline Argentina & ARG & & Kenya & KEN & \\
\hline Australia & AUS & & Korea, Rep. & KOR & \\
\hline Austria & AUT & & Lesotho & LSO & * \\
\hline Bangladesh & BGD & & Malawi & MWI & \\
\hline Barbados & BRB & * & Malaysia & MYS & \\
\hline Belgium & BEL & & Mali & MLI & \\
\hline Benin & BEN & * & Mauritius & MUS & * \\
\hline Bolivia & BOL & & Mexico & MEX & \\
\hline Botswana & BWA & & Mozambique & MOZ & \\
\hline Brazil & BRA & & Nepal & NPL & * \\
\hline Cameroon & CMR & & Netherlands & NLD & \\
\hline Canada & CAN & & New Zealand & NSZ & \\
\hline Central African Republic & $\mathrm{CAF}$ & * & Nicaragua & $\mathrm{NIC}$ & * \\
\hline Chile & $\mathrm{CHL}$ & & Niger & NER & \\
\hline China & $\mathrm{CHN}$ & & Norway & NOR & \\
\hline Colombia & $\mathrm{COL}$ & & Pakistan & PAK & \\
\hline Congo, Dem. Rep. & ZAR & & Panama & PAN & * \\
\hline Congo, Rep. & COG & & Papua New Guinea & PNG & \\
\hline Costa Rica & CRI & & Paraguay & PRY & \\
\hline Cyprus & CYP & & Peru & PER & \\
\hline Denmark & DNK & & Philippines & $\mathrm{PHL}$ & \\
\hline Dominican Republic & DOM & & Portugal & PRT & \\
\hline Ecuador & ECU & & Rwanda & RWA & * \\
\hline Egypt, Arab Rep. & EGY & & Senegal & SEN & \\
\hline El Salvador & SLV & & Sierra Leone & SLE & \\
\hline Fiji & FJI & * & Singapore & SGP & \\
\hline Finland & FIN & & South Africa & ZAF & \\
\hline France & FRA & & Spain & ESP & \\
\hline Gambia, The & GMB & & Sri Lanka & LKA & \\
\hline Germany & DEU & & Sweden & SWE & \\
\hline Ghana & GHA & & Switzerland & $\mathrm{CHE}$ & \\
\hline Greece & GRC & & Syrian Arab Republic & SYR & \\
\hline Guatemala & GTM & & Thailand & THA & \\
\hline Guyana & GUY & & Togo & TGO & \\
\hline Haiti & $\mathrm{HTI}$ & & Trinidad and Tobago & TTO & \\
\hline Honduras & HND & & Tunisia & TUN & \\
\hline Iceland & ISL & & Turkey & TUR & \\
\hline India & IND & & Uganda & UGA & \\
\hline Indonesia & IDN & & United Kingdom & GBR & \\
\hline Iran, Islamic Rep. & IRN & & United States & USA & \\
\hline Ireland & IRL & & Uruguay & URY & \\
\hline Israel & ISR & & Venezuela, RB & VEN & \\
\hline Italy & ITA & & Zambia & ZMB & \\
\hline Jamaica & JAM & & Zimbabwe & ZWE & \\
\hline
\end{tabular}




\section{References}

Barro, R J., 1990. “Government Spending in a Simple Model of Endogenous Growth,” Journal of Political Economy, S103-S125.

1991a. "Economic Growth in a Cross Section of Countries," Quarterly Journa/ of Economics, 106(2): 407-33.

1991b. "A Cross-Country Study of Growth, Saving, and Government," in B. D. Bernheim, and J. Shoven, eds., National Saving and Economic Performance, Chicago and London: University of Chicago Press, pp. 271-301.

and X. Sala-i-Martin, 1995, Economic Growth, MIT Press.

Chowdhury, A.R., 1991. "A Casual Analysis of Defense Spending and Economic Growth," Journal of Conflict Resolution, 35(1): 80-97.

Davoodi, H., B. Clements, J. Schiff, and P. Debaere, 2001. Military Spending, the Peace Dividend, and Fiscal Adjustment," IMF Staff Papers 48: 290-316.

Epstein, M. J., 1997. Nonlinear Dynamics, Mathematical Biology, and Social Science, AddisonWesley/Santa Fe Institute.

Gupta, S., L. de Mello, and R. Sharan, 2000. "Corruption and Military Spending," IMF Working Paper No. 00/23.

Happe, N. and J. Wakeman-Linn, 1994. "Military Expenditure and Arms Trade: Alternative Data Sources," IMF Working Paper 94/69.

Hewitt, D., 1992. "Military Expenditures Worldwide: Determinants and Trends, 1972-1988, Journal of Public Policy, 12: 105-52.

Hirshleifer, J., 1995. "Theorizing about Conflict,” in K. Hartley and T. Sandler (eds.), Handbook of Defense_Economics, Vol. 1, Elsevier.

Knight, M., N. Loayza, and D. Villanueva, 1996. "The Peace Dividend: Military Spending Cuts and Economic Growth." IMF Staff Papers 43 (1): 1-37.

Landau, D., 1996. "Is the Peace Dividend Negative: Military Expenditure and Economic Growth in the Wealthy OECD Countries" Quarterly Review of Economics and Finance, 36(2): 183-96.

Lucas, E. R., 1993. “Making a Miracle,” Econometrica, 61: 251-72.

Mauro, P., 1995. "Corruption and Growth," Quarterly Journal of Economics, 110 (August): 681712.

Mintz, A., and R.T. Stevenson, 1995. "Defense Expenditure, Economic Growth and the 'Peace Dividend'," Journal of Conflict Resolution, 39(2): 283-305. 
Ram, R., 1995. "Defense Expenditure and Economic Growth," in K. Hartley and T. Sandler (eds.) Handbook of Defense_Economics, Vol. 1, Elsevier.

Skaperdas, S., 1996. "Contest Success Functions," Economic Theory, 7 (February): 283-290.

Tanzi, V. and H. Davoodi, 1997. "Corruption, Public Investment, and Growth,” IMF Working Paper 97/139.

, 2000. “Corruption, Growth, and Public Finances,” IMF Working Paper 00/182.

van Wijnbergen, S., 1984. “The 'Dutch Disease': A Disease After All?” Economic Journal, 94: 41-55. 
Table 1. Summary Statistics

\begin{tabular}{|c|c|c|c|c|c|}
\hline & Mean & Std. Dev. & Min & Max & \# of cos. \\
\hline mil & 3.80 & 5.31 & 0.00 & 40.42 & 133 \\
\hline thr & 0.90 & 2.36 & 0.00 & 15.00 & 133 \\
\hline$g y$ & 1.34 & 2.65 & -9.09 & 9.56 & 117 \\
\hline $\operatorname{lgdp}$ & 8.09 & 1.02 & 6.36 & 9.92 & 110 \\
\hline gpop & 1.92 & 0.96 & -0.03 & 4.37 & 116 \\
\hline leduc & 1.03 & 0.91 & -1.97 & 2.40 & 99 \\
\hline inv/gdp & 14.38 & 7.79 & 2.49 & 44.06 & 111 \\
\hline
\end{tabular}

Note: $g y$ is the annual average real per capita GDP growth, 1989-98; mil is the military spending/GDP ratio; thr measures a country's external military threat; lgdp is the log of initial real per capita GDP; leduc is log of initial years of male schooling; gpop is population growth rate; and inv/gdp is the investment/GDP ratio. 
Table 2. Determinants of Growth, Military Spending and External Threats

\begin{tabular}{|c|c|c|c|c|c|c|}
\hline & (1) & & $(2)$ & & (3) & \\
\hline \multirow[t]{2}{*}{ mil } & -0.08 & & -0.26 & & -0.56 & $* \star *$ \\
\hline & $(0.15)$ & & $(0.16)$ & & $(0.20)$ & \\
\hline \multirow[t]{2}{*}{ thr } & & & 0.39 & $\star \star *$ & -0.20 & \\
\hline & & & $(0.15)$ & & $(0.28)$ & \\
\hline \multirow[t]{2}{*}{ mil ${ }^{*} t h r$} & & & & & 0.16 & $* *$ \\
\hline & & & & & $(0.06)$ & \\
\hline \multirow[t]{2}{*}{$\lg d p$} & -1.59 & $\star * *$ & -1.55 & $* * *$ & -1.90 & $* * *$ \\
\hline & $(0.44)$ & & $(0.43)$ & & $(0.44)$ & \\
\hline \multirow[t]{2}{*}{ leduc } & 0.74 & * & 0.69 & * & 0.70 & * \\
\hline & $(0.43)$ & & $(0.41)$ & & $(0.40)$ & \\
\hline \multirow[t]{2}{*}{ gpop } & -1.04 & $* * *$ & -1.04 & $* * *$ & -1.28 & $* * *$ \\
\hline & $(0.40)$ & & $(0.38)$ & & $(0.39)$ & \\
\hline \multirow[t]{2}{*}{ inv/gdp } & 0.13 & $\star \star \star *$ & 0.12 & $\star * *$ & 0.14 & *** \\
\hline & $(0.04)$ & & $(0.04)$ & & $(0.04)$ & \\
\hline \multirow[t]{2}{*}{ constant } & 13.71 & $\star * *$ & 13.84 & $\star \star \star *$ & 17.55 & $\star * *$ \\
\hline & (3.62) & & $(3.50)$ & & (3.72) & \\
\hline \# of cos. & 91 & & 91 & & 91 & \\
\hline Adj R2 & 0.24 & & 0.29 & & 0.33 & \\
\hline
\end{tabular}

Notes: Estimation by OLS. Standard errors in parentheses. ${ }^{* * *}$ indicates significance at $1 \%,{ }^{* *}$ at $5 \%,{ }^{*}$ at $10 \%$. Dependent variable is $g y$, the annual average real per capita GDP growth over 1989-98. Explanatory variables include mil, military spending/GDP; thr, a measure of a country's external military threat; mil*thr, an interaction of the two variables; lgdp, log of initial real per capita GDP; leduc, log of initial years of male schooling; gpop, population growth rate; and inv/gdp, the investment/GDP ratio. 
Table 3. Determinants of Growth, Military Spending and Corruption

\begin{tabular}{|c|c|c|c|c|c|c|}
\hline & (1) & & (2) & & (3) & \\
\hline mil & & & $\begin{array}{l}-0.03 \\
(0.14)\end{array}$ & & $\begin{array}{l}-1.27 \\
(0.31)\end{array}$ & $\star \star \star *$ \\
\hline goodgov & $\begin{array}{c}0.51 \\
(0.17)\end{array}$ & $\star * *$ & $\begin{array}{c}0.50 \\
(0.17)\end{array}$ & ** & $\begin{array}{l}-0.04 \\
(0.20)\end{array}$ & \\
\hline mil $^{*}$ goodgov & & & & & 0.20 & $* * *$ \\
\hline & & & & & (0.05) & \\
\hline $\lg d p$ & $\begin{array}{l}-2.54 \\
(0.46)\end{array}$ & $\star \star \star *$ & $\begin{array}{l}-2.48 \\
(0.47)\end{array}$ & $* * *$ & $\begin{array}{l}-2.51 \\
(0.42)\end{array}$ & $\star * *$ \\
\hline leduc & $\begin{array}{c}0.20 \\
(0.45)\end{array}$ & & $\begin{array}{c}0.17 \\
(0.46)\end{array}$ & & $\begin{array}{c}0.18 \\
(0.41)\end{array}$ & \\
\hline gpop & $\begin{array}{l}-0.88 \\
(0.32)\end{array}$ & $\star * *$ & $\begin{array}{l}-0.81 \\
(0.37)\end{array}$ & ** & $\begin{array}{l}-0.91 \\
(0.33)\end{array}$ & $* * *$ \\
\hline inv/gdp & $\begin{array}{c}0.04 \\
(0.04)\end{array}$ & & $\begin{array}{c}0.05 \\
(0.04)\end{array}$ & & $\begin{array}{c}0.07 \\
(0.04)\end{array}$ & * \\
\hline africa & $\begin{array}{l}-3.81 \\
(0.76)\end{array}$ & $* * *$ & $\begin{array}{l}-3.79 \\
(0.77)\end{array}$ & $\star \star *$ & $\begin{array}{l}-3.35 \\
(0.70)\end{array}$ & $\star * *$ \\
\hline constant & $\begin{array}{c}21.02 \\
(3.48)\end{array}$ & $\star \star \star *$ & $\begin{array}{r}20.46 \\
(3.56)\end{array}$ & $* * *$ & $\begin{array}{c}23.84 \\
(3.29)\end{array}$ & $* * *$ \\
\hline \# of cos. & 83 & & 81 & & 81 & \\
\hline Adj R2 & 0.44 & & 0.42 & & 0.53 & \\
\hline
\end{tabular}

Notes: Estimation by OLS. Standard errors in parentheses. ${ }^{* \star *}$ indicates significance at $1 \%,{ }^{* *}$ at $5 \%,{ }^{*}$ at $10 \%$. Dependent variable is $g y$, the annual average real per capita GDP growth over 1989-98. Explanatory variables include mil, military spending/GDP; goodgov, a measure of corruption (higher values denote less corruption and better government); mil $^{*}$ goodgov, an interaction of the two variables; lgdp, log of initial real per capita GDP; leduc, log of initial years of male schooling; gpop, population growth rate; inv/gdp, the investment/GDP ratio; and Africa, dummy for sub-Saharan African countries. 
Table 4. Determinants of Growth, Military Spending, External Threats, and Corruption

\begin{tabular}{|c|c|c|c|}
\hline & $\begin{array}{c}\text { Low } \\
\text { Goodgov } \\
\text { (1) }\end{array}$ & & $\begin{array}{c}\text { High } \\
\text { Goodgov } \\
\text { (2) }\end{array}$ \\
\hline mil & $\begin{array}{l}-0.81 \\
(0.30)\end{array}$ & $* * *$ & $\begin{array}{c}0.19 \\
(0.22)\end{array}$ \\
\hline thr & $\begin{array}{l}-0.31 \\
(0.43)\end{array}$ & & $\begin{array}{l}-0.06 \\
(0.26)\end{array}$ \\
\hline mil*thr & $\begin{array}{c}0.22 \\
(0.10)\end{array}$ & ** & $\begin{array}{c}0.00 \\
(0.06)\end{array}$ \\
\hline $\operatorname{lgdp}$ & $\begin{array}{l}-1.89 \\
(0.64)\end{array}$ & $* \star *$ & $\begin{array}{l}-2.40 \\
(0.53)\end{array}$ \\
\hline leduc & $\begin{array}{c}0.87 \\
(0.60)\end{array}$ & & $\begin{array}{c}1.13 \\
(0.71)\end{array}$ \\
\hline gpop & $\begin{array}{l}-1.99 \\
(0.59)\end{array}$ & $* * *$ & $\begin{array}{c}-0.42 \\
(0.37)\end{array}$ \\
\hline $\operatorname{lnv} / g d p$ & $\begin{array}{c}0.06 \\
(0.09)\end{array}$ & & $\begin{array}{c}0.10 \\
(0.04)\end{array}$ \\
\hline constant & $\begin{array}{l}20.27 \\
(5.43)\end{array}$ & $* * *$ & $\begin{array}{l}19.95 \\
(4.40)\end{array}$ \\
\hline \# of cos. & 49 & & 32 \\
\hline Adj R2 & 0.36 & & 0.52 \\
\hline
\end{tabular}

Notes: Estimation by OLS. Standard errors in parentheses. ${ }^{* * *}$ indicates significance at $1 \%,{ }^{* *}$ at $5 \%,{ }^{*}$ at $10 \%$. Dependent variable is $g y$, annual average real per capita GDP growth over 1989-98. Explanatory variables include mil, military spending/GDP; thr, external threat; mi $^{*}$ thr , interaction variable; lgdp, log of initial real per capita GDP; leduc, log of initial years of male schooling; gpop, population growth rate; and inv/gdp, investment/GDP ratio. Subsamples defined by goodgov level, a measure of corruption (higher values denote less corruption and better government) relative to sample mean: low goodgov (goodgov $<6.0$ ) and high goodgov (goodgov > 6.0). 
Figure 1. Thr vs. Mil

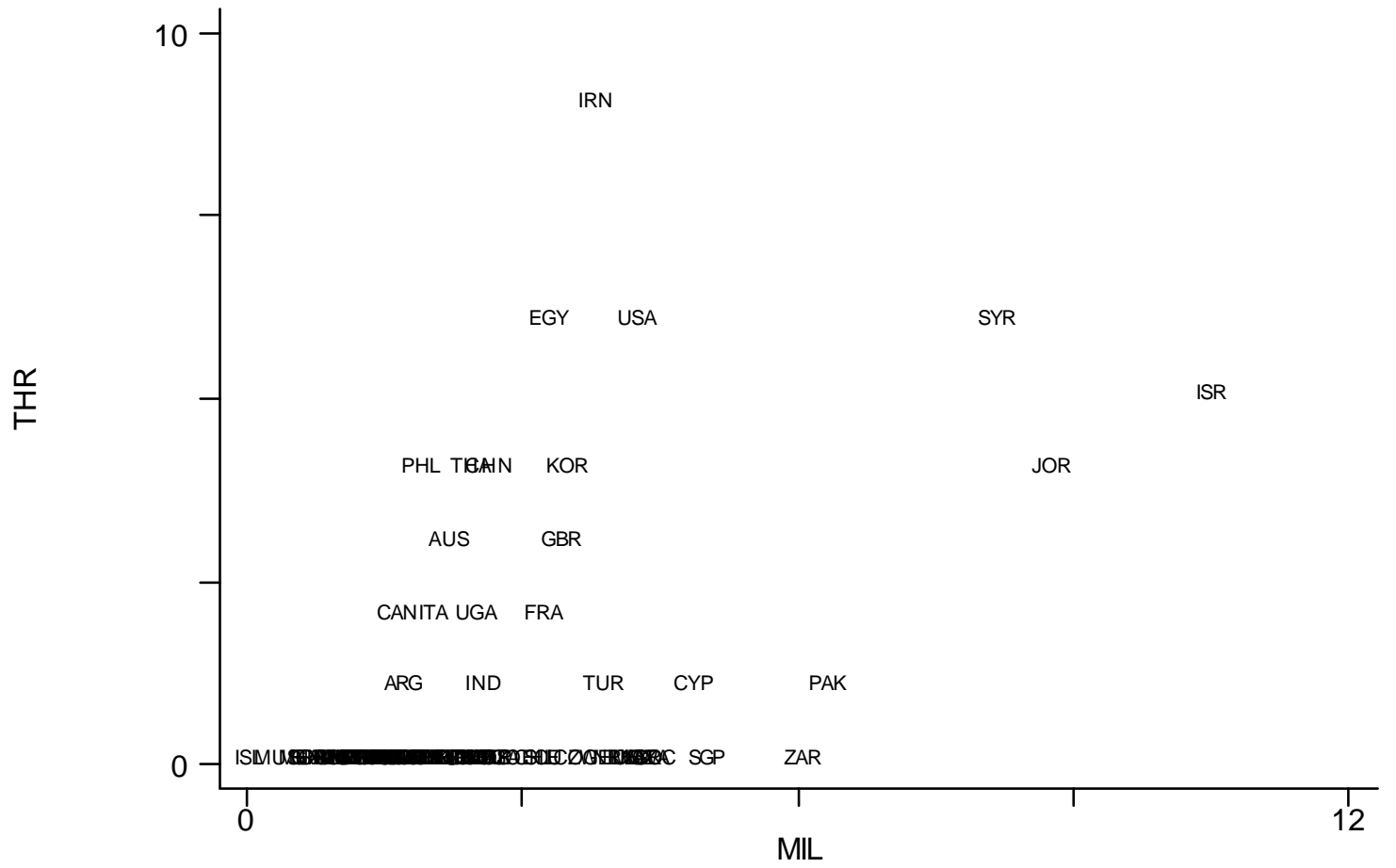

Note: mil is military spending/GDP; thr measures a country's external military threat. Observations plotted for the 81 countries with data available for all variables in the regressions in Table 2. 
Figure 2. Conditional Correlation between Growth and Military Spending, Controlling for External Threats

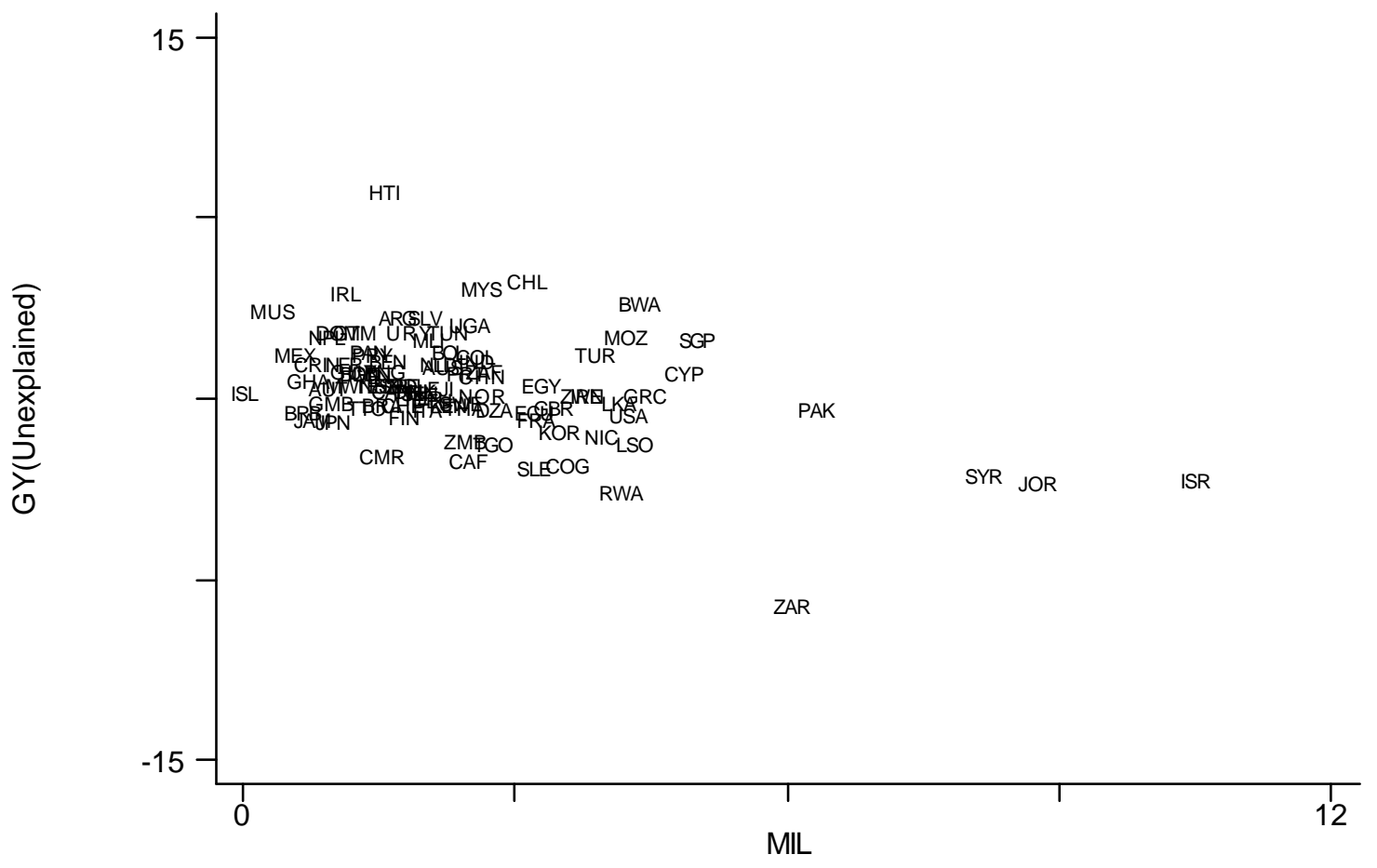

Note: Conditional correlation calculated from regression for gy that contains all of the explanatory variables in Table 2, column (3), including mil, thr, and mil*thr. The variable plotted on the vertical axis is the unexplained part of $g y$ after filtering out the effects of all of the explanatory variables except mil. 
Figure 3. Conditional Correlation between Growth and Military Spending

\section{a. Low External Threat Countries}

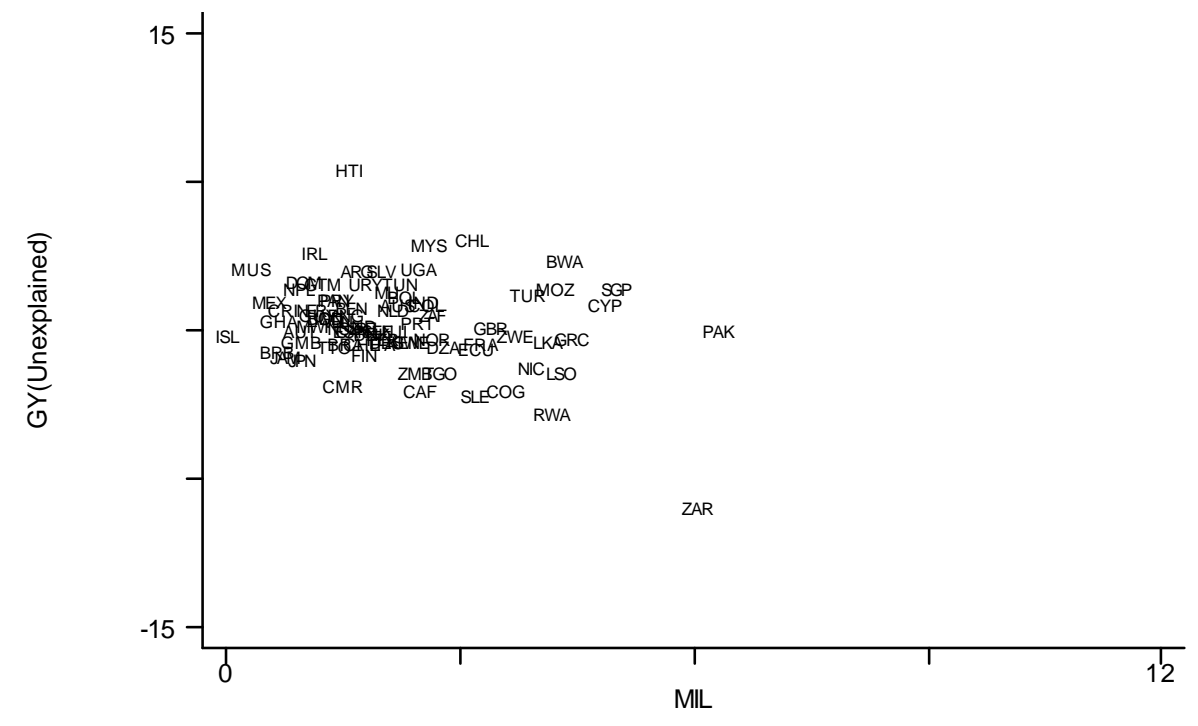

\section{b. High External Threat Countries}

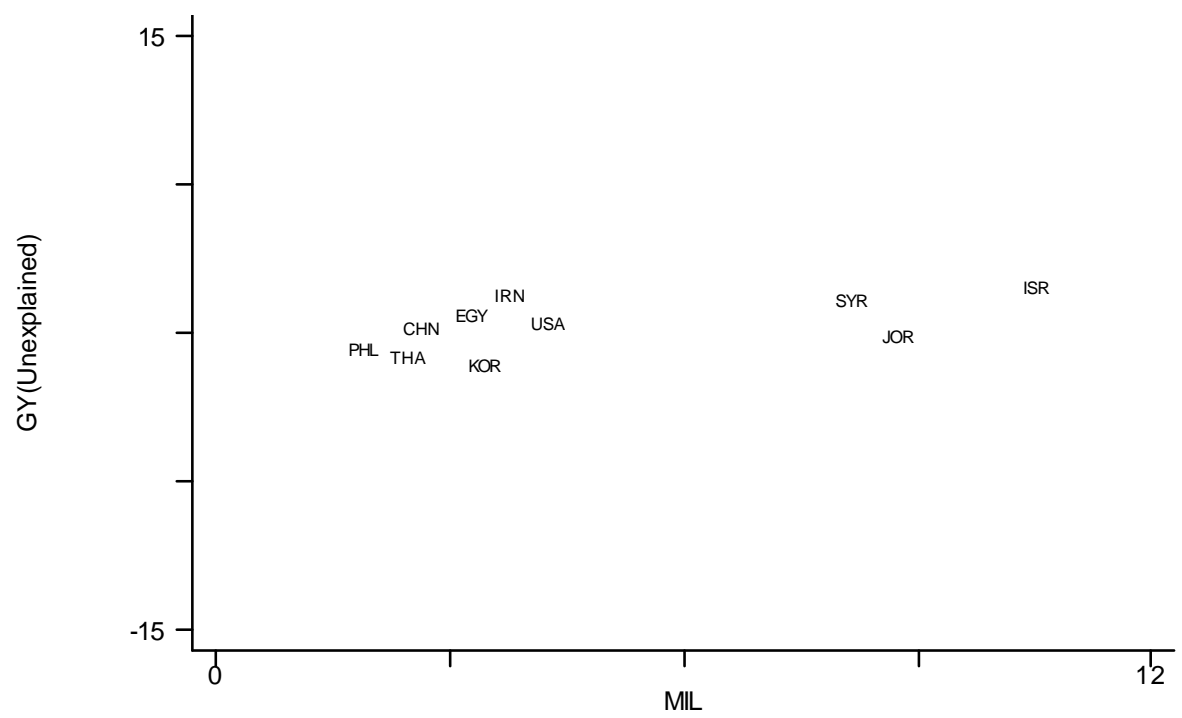

Note: Conditional correlation calculated from a regression for gy that contains all of the growth variable controls in Table 2 as well as mil*lowthr and mil*highthr, where lowthr is a dummy defined equal to 1 for countries with a level of thr $<3.5$.and highthr is a dummy defined equal to 1 for countries with level of $t h r>3.5$. (The dummies are also included as separate intercepts in the regression.) Panel a plots on the vertical axis the unexplained part of $g y$ after filtering out the contribution of all variables except mil*lowthr; panel b filters out the effects of all variables except mil*highthr . 


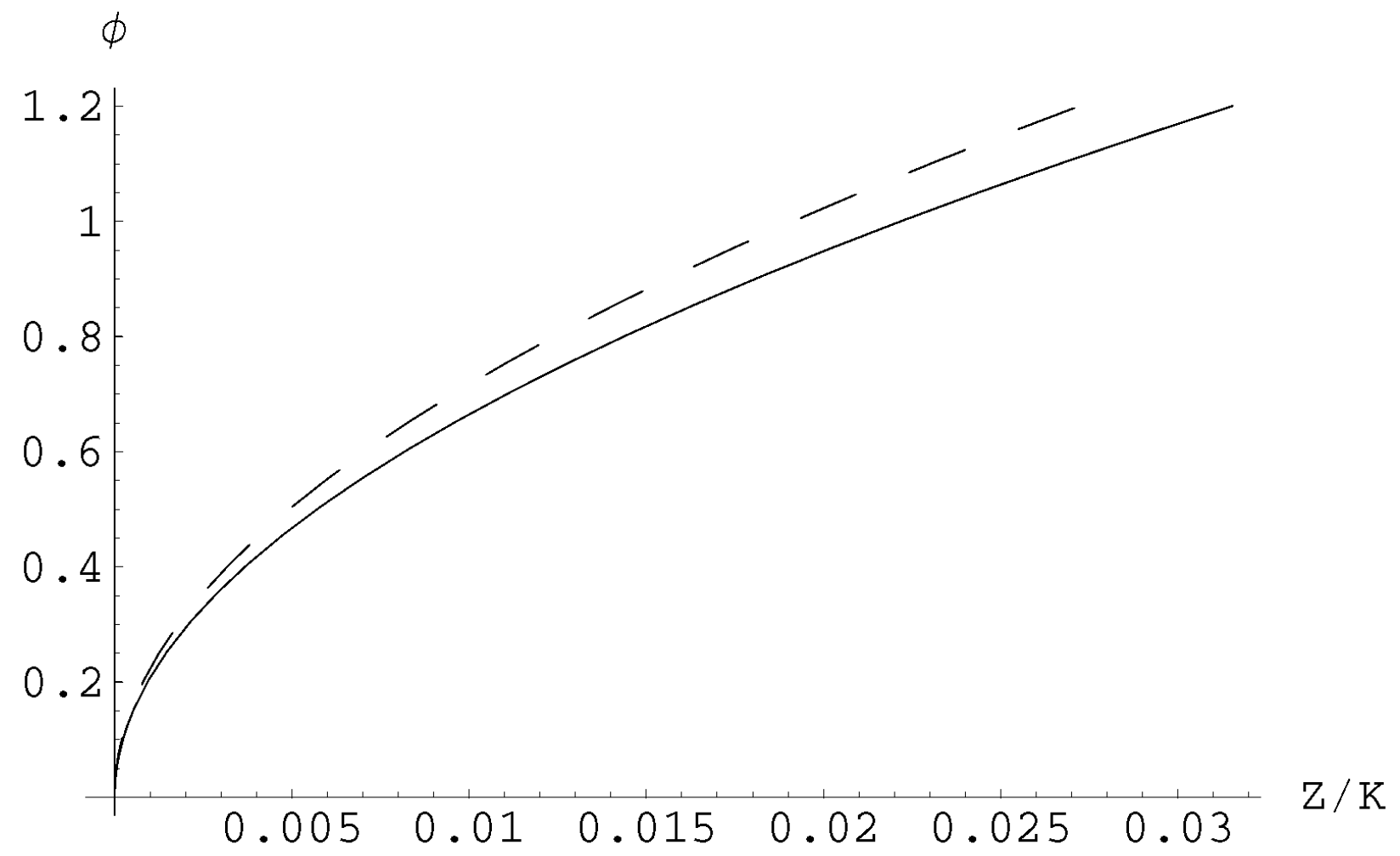

Note: $\phi$ is the optimal ratio of military spending to non-military spending; $z / k$ denotes the external threat level (normalized by the capital stock). The plots are calibrated by assuming $A=1, \alpha=.2$, and $t_{c}$ set equal to .1 (solid line) or .2 (dashed line). 


\section{Figure 5. Optimal Growth and Military Spending}

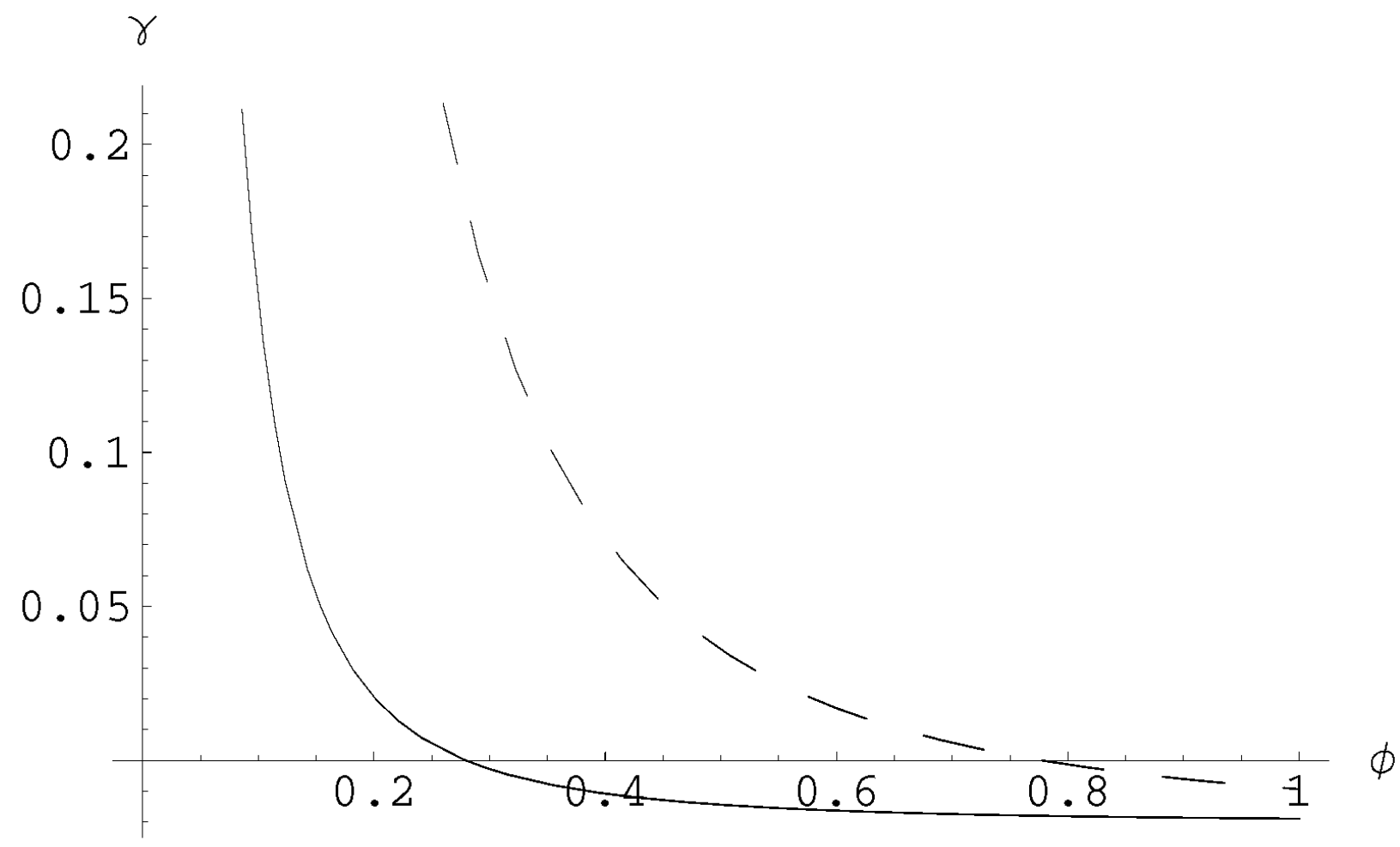

Note: $\gamma$ is the optimal growth rate; $\phi$ is the optimal ratio of military spending to nonmilitary spending. Plots are calibrated by assuming $\alpha=.2, t_{c}=.1, \sigma=1, \rho=.02$, $z / k=.0001$ (solid line), $z / k=.001$ (dashed line), and parametrically varying $A$ to determine $\tilde{\phi}$ through equations (8a) and (A10) in the appendix. 
Figure 6. Goodgov vs. mil

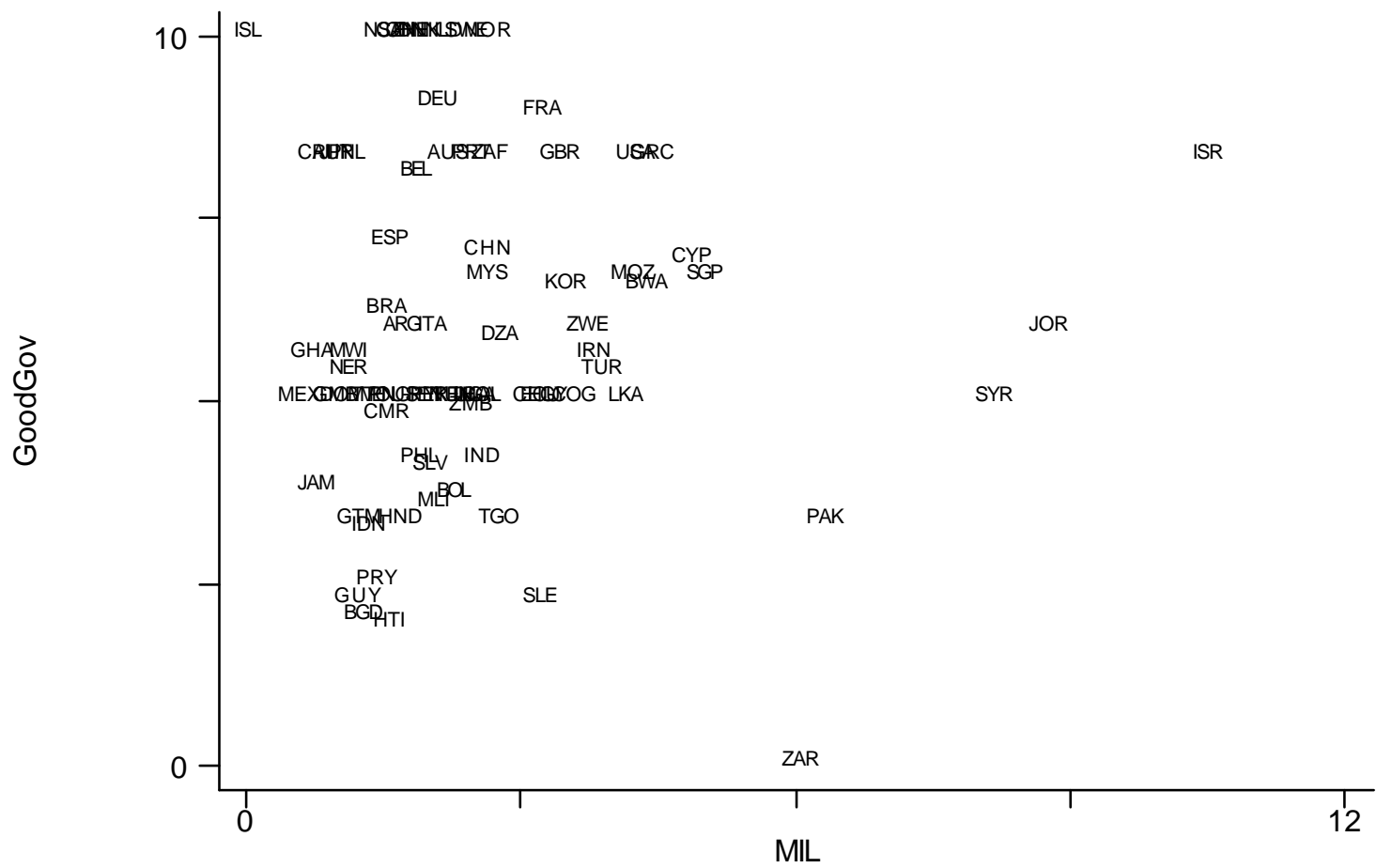

Note: mil is military spending/GDP; goodgov measures a country's level of good government. Observations plotted for the 81 countries with data available for all variables in the regression results reported in column (3) of Table 3. 


\section{Figure 7. Conditional Correlation between Growth and Military Spending, Controlling for Corruption}

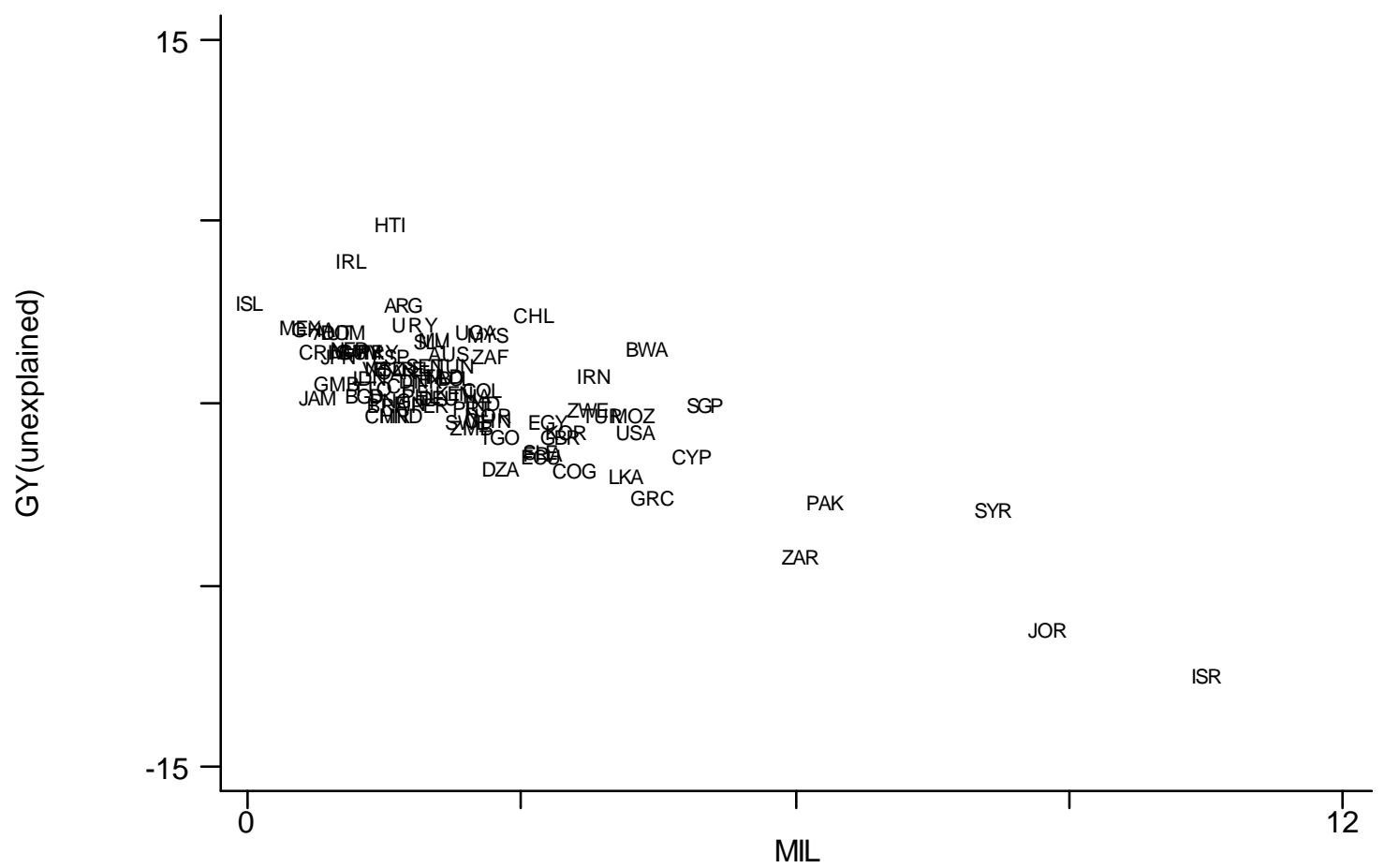

Note: Conditional correlation calculated from regression for $g y$ that contains all of the explanatory variables in Table 3, column (3), including mil, goodgov, and mil*goodgov. The variable plotted on the vertical axis is the unexplained part of $g y$ after filtering out the effects of all of the explanatory variables except thr. 